\title{
Psychological Well-Being in Health Sciences Students: Some Clinical and Educational Issues
}

\author{
Porta-Nova $\mathbf{R}^{*}$ \\ Health Higher School of the Portuguese Red Cross, in Lisbon, Portugal
}

*Corresponding author: Rui Porta-Nova, Health Higher School of the Portuguese

Red Cross, in Lisbon, Portugal, Email: rnova@esscvp.eu
Mini review

Volume 2 Issue 4

Received Date: July 26, 2017

Published Date: September 11, 2017

\section{Introduction}

The frequency of Higher Education, implies different levels of requirements and experiences (academic life experiences), conditioning adaptation, that may compromise psychological well-being and mental health $[1,2]$. The student needs effective personal skills, to promote adaptation and enable the successful achievement of developmental and academic tasks [3].

Training in the area of health sciences is psychologically demanding and distressing. In particularly, there are some cognitive demands (e.g. to acquire knowledge which are intensively evaluated) and personal requirements (e.g. being able to cope with human suffering) [4]. Academic distress in health sciences students is cause of: depressive and anxiety disorders [5]; increased consumption of substances [6]; changes in mental health accompanied by physical illness [7] and academic failure and dropout [8].

The purpose of this article is to reflect, based on evidence and daily experience, as a professor of Higher Education and Clinical Psychologist, on some aspects that we consider relevant for the promotion of psychological well-being in health students. The consideration of these aspects seems to us fundamental as a logical corollary of a process of interrogation about the daily reality with which we work and that we intend to know and understand, so that our professional performance can receive accruals of competence. In this perspective, we structure our reflection around the clinical dimension and the educational dimension.

Thus, our analysis seeks to bring some added value to the knowledge and dissemination on this issue, highlighting specifics and defining approaches that allow the construction of coherent models of action at clinical and educational level, which in our opinion should not be seen in isolation, but in interrelation.

\section{Clinical Issues}

Firstly, in a clinical approach, we want to emphasize the importance of interventions focused on the person of the young student, understood as being holistic in development. In this regard, is very important the understanding of the development process in terms of vectors associated with the different stages of personal and academic/curricular growth. Since the management of competencies and emotions, through the construction of autonomy and identity, until the construction of solid values and personal integrity $[1,3]$.

In our previous research [9], we have verified that there are risk factors in this population that must be considered and that affect not only the student as a person, but also condition their way of relating and their performance Academic, that is, they call into question the opportunity to be adapted.

Of course, in the first line of approach, it is incumbent on us to list these risk factors. Thus, attending the 1st year, in the course of Physical Therapy, belong to the female gender, be dislocated, have a lower career expectancy, not be autonomous, present a negative perception of their cognitive skills, less self-confidence, decrease in good - psychological and/or physical distress, academic difficulties resulting from inconsistent prior academic knowledge bases and high levels of anxiety in assessment situations. These factors constitute characteristics that, alone or together, should receive special attention from the academic structures of higher education institutions, namely, management bodies, 


\section{Psychology \& Psychological Research International Journal}

teachers and academic services, which would highlight counseling and psychological support services [9].

It was also clear in our study $[9,10]$ what is the needs of these students in terms of Mental Health are, both from the point of view of factors related to academic life; and from the point of view of their personal competences, such as: the need to have a positive self-esteem, to perceive oneself intellectually competent, to have and maintain stable relationships with parents, to feel satisfied with their self-image and sentimental ties with another person. It is possible to differentiate areas in which psychological intervention can (and should) act. We would first emphasize the interventions that are oriented to risk factors of mental illness or to psychopathological problems already manifested.

In relation to mental illness risk factors, preventive approaches developed by the psychological support and counseling services of the institutions $[11,12]$ are advised and, if they do not yet exist, priority should be given to $[13,14]$.

An example of preventive intervention may be to increase the control and management of anxiety in assessments through practical mini-courses in which students develop skills in self-control and management of anxiety.

Concerning interventions aimed at students with changes in their psychological well-being, it is important to promote accessibility to counseling and support services, and it is found that students with health problems sometimes resist seeking help for fear of stigmatization or other consequences that limit the achievement of your academic / professional goals $[15,16]$. However, students generally recognize the importance of these services and the need for them to operate visibly on their intervention skills and ease of access to them [17].

Of course, these services must always respect all the deontological and ethical rules of clinical psychology (namely respect for confidentiality and secrecy), and it is essential that evidence-based intervention protocols be established, which should allow for rigor, objectivity and effectiveness in resolution problems.

In this sense, Helkowski, Stout and Jongsma presents [18] a set of twenty-eight protocols, which the authors refers to as "treatment plans", especially aimed at psychological intervention in Higher Education, covering most of the common problems in young university students. In general terms, all protocols should follow an intervention model based on six steps: problem selection (with the twenty-eight identified problems as a reference); problem definition; definition of objectives to be achieved with the intervention; construction of strategy(s) according to defined objectives; definition of the type of intervention (e.g. psychotherapy) and determination of a diagnosis (according to international diagnostic criteria).

Larger programs can be implemented in institutions that are designed to support the student in confronting stress and anxiety [19]. Some of these programs have been tested, with very positive results in medical students, from the first to the last year of the course [2023].

Other programs are designed to promote Mental Health $[24,25]$, with healthy students to be healthy professionals in the future [26].

\section{Educational Issues}

From an educational point of view, some interventions aimed at academic difficulties (e.g. poor knowledge bases for the course attended), benefit from models and support programs of an educational, pedagogical and didactic nature, such as mentoring and [27] also psychological approaches related to the development of social and cognitive competences [28].

Students with general problems of integration and adaptation can improve their levels of adaptation through specific programs such as mentoring, or peer counseling $[11,12,29]$, or programs such as the "family day", which allow family members or other significant persons to the student, a contact with the institution, namely during the pre-registration process in Higher Education, aimed at improving the general knowledge of the course and school, reducing future student stress levels, and increasing social support [30].

Still in the educational and pedagogical level, in both aspects of vocational nature and promotion of academic adaptation, initiatives that promote the knowledge of health institutions and courses among the pre-university population, seem to be of great interest, such as the "open day "in Higher Education Institutions, can contribute to the consistency of the vocational decision process [31]. 


\section{Psychology \& Psychological Research International Journal}

We believe that teachers have a central role in promoting academic adaptation and, in particular, in school success [32].

It is important to emphasize the need for pedagogical (and not just scientific) training for higher education teachers. This training, we believe, will overcome some limitations related to the pedagogical methodologies used, such as the substitution of essentially expository methods, by active methods, that promote the student's active involvement in the teaching-learning process, making the relation [33], and allow new approaches to the system of evaluation of students' work, and should enable them to evaluate the work as well of teachers, in an understanding of continuous improvement of the educational process and of facilitating the socialization of the student to the institution and to the course, and of identification with the future profession in the health area [34-36].

\section{Conclusion}

In this brief approach we have tried to describe some aspects that result from the interpellation, reflection and investigation that the daily contact with young adult students of the Higher Education of Health Sciences has provided us. Being limited in its content, our approach has no more than the pretension to emphasize dimensions that synergistically associate, constituting in the same group of factors promoting (or conditioning) of the psychological well-being and of the academic adaptation, being reinforced of this in this way, the perspective in which healthy and adapted students will be more likely to be professionals better able to cope with the demands of their future professions.

\section{References}

1. Chickering AW, Reisser L (1993) Education and identity. San Francisco: Jossey-Bass.

2. Pascarella ET, Terenzini PT (2005) How college affects students: A third decade of research. San Francisco: Jossey-Bass 2.

3. Evans NJ, Forney DS, Guido-Dibrito F (1998) Student development in college: Theory, research and practice. San Francisco: Jossey-Bass.

4. Porta-Nova R (2016) Risk factors for mental health in higher education students of health sciences. BMC Health Services Research 16 (S3): 027.
5. Dyrbye LN, Thomas MR, Shanafelt TD (2006) Systematic review of depression, anxiety, and other indicators of psychological distress among US and Canadian medical students. Academic Medicine 81(4): 354-373.

6. Perales A, Sogi C Morales R (2003) Estúdio comparativo de salud mental en estudiantes de medicina de dos universidades estatales Peruanas. Anales de la Faculdad de Medicina 64 (4): 239-246.

7. Roberts LW, Warner TD, Lyketsos C, Frank E, Ganzini L et al. (2001) Perceptions of academic vulnerability associated with personal illness: A study of 1,027 students at nine medical schools Collaborative Research Group on Medical Student Health. Comprehensive Psychiatry 42 (1): 1-15.

8. Ross S, Cleland J, Macleod MJ (2006) Stress, debt and undergraduate medical student performance. Medical Education 40(6): 584-589.

9. Porta-Nova R (2009) Adaptability, personal skills and psychological well-being of young people from higher education in the area of health sciences. $\mathrm{PhD}$ thesis submitted to the Abel Salazar Institute of Biomedical Sciences, University of Porto.

10. Porta-Nova R, Fleming M (2009) Vivências académicas, competências pessoais e saúde mental em estudantes de ciências da saúde. Psicologia 23(1): 165-183.

11. Archer JJr, Cooper S (1998) Counseling and mental health services on campus: A handbook of contemporary practices and challenges. San Francisco: Jossey-Bass.

12. Lore CJ (1997) Student mental health and funding constraints: A delicate balance. Journal of American College Health 46 (1): 43-46.

13. Izutsu S, Hishinuma ES (2005) Role of psychologists in academic medicine. Journal of Clinical Psychology in Medical Settings 12(3): 257-264.

14. Pasnau RO, Stoessel P (1994) Mental health service for medical students. Medical Education 28(1): 33-39.

15. Brimstone R, Thistlethwaite JE, Quirk F (2007) Behavior of medical students in seeking mental and physical health care: Exploration and comparison 


\section{Psychology \& Psychological Research International Journal}

with psychology students. Medical Education 41(1): 74-83.

16. Chew-Graham CA, Rogers A, Yassin N (2003) I wouldn't want it on my cv or their records: Medical students' experiences of help-seeking for mental health problems. Medical Education 37(10): 873-880.

17. Plaut SM, Maxwell SA, Seng L, O'Brien JJ, Fairclough GF (1993) Mental health services for medical students: Perceptions of students, student affairs deans, and mental health providers. Academic Medicine 68 (5): 360-365.

18. Helkowski C, Stout CE, Jongsma AE (2004) The college student counseling treatment planner. Hoboken, NJ: John Wiley \& Sons.

19. Wolf TM (1994) Stress, coping and health: Enhancing well-being during medical school. Medical Education 28(1): 8-17.

20. Coombs RH, Virshup BB (1994) Enhancing the psychological health of medical students: the student well-being committee. Medical Education 28(1): 4754.

21. Finkelstein C, Brownstein A, Scott C, Lan Y (2007) Anxiety and stress reduction in medical education: An intervention. Medical Education 41(3): 258-264.

22. Rubin DC, Feeney C (1986) A multicomponent stress management program for college students. Journal of Counseling and Development 64(8): 531.

23. Rubio C, Lubin B (1986) College student mental health: A person-environment interactional analysis. Journal of Clinical Psychology 42 (1): 205-212.

24. Tennant C (2002) A student mental health and welfare program in a medical faculty. The Medical Journal of Australia 177 (1): S9-S11.

25. Wolf TM, Scurria PL (1995) A survey of health promotion programs in U. S. and Canadian medical schools. American Journal of Health Promotion 10 (2): 89-91.

26. Cameron D, Katch E, Anderson P, Furlong MA (2004) Health doctors, healthy communities. Journal of Ambulatory Care Management 27(4): 328-338.
27. Sayer M, Saintonge MC, Evans D \& Wood D (2002) Support for students with academic difficulties. Medical Education 36(7): 643-650.

28. Ducey CP (2006) Academic difficulties.In P. A. Grayson \& P. W. Meilman (Eds.), College mental health practice (pp. 173-193). New York: Routledge.

29. Hauer KE, Teherani A, Dechet A, Aagaard M (2005) Medical students' perceptions of mentoring: A focusgroup analysis. Medical Teacher 27 (8): 732-739.

30. Bell MA, Smith PS, Brokaw JJ, Cushung HE (2004) A family day program enhances knowledge about medical school culture and necessary supports. BMC Medical Education 4 (3): 1-3.

31. Loureiro E, Lourinho I, Ferreira MA (2007) O dia aberto da FMUP: Contributo para o processo de tomada de decisão vocacional dos alunos do ensino secundário. Arquivos de Medicina 21 (3/4): 83-89.

32. Jeffreys MR (2004) Nursing student retention: Understanding the process and making a difference. New York: Springer Publishing Company

33. Sinclair HK, Cleland JA (2007) Undergraduate medical students: Who seeks formative feedback? Medical Education 41(6): 580-582.

34. Antunes L (2007) Processo e trajectórias de socialização em enfermagem: Uma reflexão sociológica sobre a construção de identidades sociais e profissionais dos estudantes. In Rodrigues $\mathrm{A}$, Nascimento C, Antunes L, Mestrinho MG, Serra M, Madeira R, Canário R, Lopes V (Autores), Processos de formação na e para a prática de cuidados. Loures, Lusociênciapp. 93-123.

35. Marques MF (2005) Entre a continuidade e a inovação. 0 ensino superior de enfermagem e as práticas pedagógicas dos professores de enfermagem. Revista Lusófona de Educação 5: 153-171.

36. Tavares J, Pereira AS, Gomes AA, Monteiro S, Gomes A (2007) Manual de psicologia do desenvolvimento e aprendizagem. Porto: Porto Editora. 